\title{
Associação da fotobiomodulação e hialuronidase tópica no extravasamento de paclitaxel: estudo de caso
}

\author{
Association of photobiomodulation and topic hyaluronidase in paclitaxel extravasation: case study
}

Asociación de fotobiomodulación y tema hialuronidasa en extravasación de paclitaxel: estudio de

caso

Recebido: 06/10/2021 | Revisado: 13/10/2021 | Aceito: 19/10/2021 | Publicado: 21/10/2021

Talita Oliveira de Lima

ORCID: https://orcid.org/0000-0002-6617-6514 Hospital das Clínicas de Botucatu, Brasil

E-mail: talima.2111@gmail.com

Wabison Junior Fernandes dos Santos

ORCID: https://orcid.org/0000-0002-6322-9529 Hospital Israelita Albert Einstein, Brasil

E-mail: wabison.santos@einstein.br

Mayara Spin

ORCID: https://orcid.org/0000-0003-4545-608X Universidade Estadual Paulista Júlio de Mesquita Filho, Brasil E-mail: mayara.spin@unesp.br

Kyara Marcondes Sardeli

ORCID: https://orcid.org/0000-0002-6932-3380 Universidade Estadual Paulista Júlio de Mesquita Filho, Brasil E-mail: kyarasardeli@hotmail.com

Karina Alexandra Batista da Silva Freitas ORCID: https://orcid.org/0000-0002-3413-8468 Hospital das Clínicas de Botucatu, Brasil E-mail: k.freitas@unesp.br

\begin{abstract}
Resumo
Objetivo: Demonstrar o uso da associação da fotobiomodulação com a hialuronidase tópica, no extravasamento de paclitaxel. Método: Estudo de caso referente a utilização da fotobiomodulação e da hialuronidase tópica em um extravasamento de paclitaxel ocorrido no ambulatório de oncologia de um hospital universitário. Após $450 \mathrm{ml}$ de infusão do paclitaxel, observou-se parada da bomba de infusão, edema no local e constatou-se deslocamento de parte do cateter do local da punção. Paciente negou queixas álgicas no local e relatou que somente observou o edema no mesmo momento da equipe de enfermagem A área foi demarcada e apresentou medida aproximada de $3,5 \mathrm{x} 3,0 \mathrm{~cm}$ (altura x largura). Resultados: Após a constatação do extravasamento, foi realizado todas as medidas necessárias, seguindo-se o protocolo institucional. Foram realizados 9 pontos de fotobiomodulação utilizando-se como densidade de energia 1 joule $/ \mathrm{cm}^{2}$, após, foi administrada hialuronidase tópica $65 \mathrm{UTR} / \mathrm{g}$. Paciente foi orientado quanto aos cuidados domiciliares. Conclusão: A associação da FBM com a hialuronidase tópica, manteve a integridade da pele do paciente, não formando lesões decorrentes do extravasamento.
\end{abstract}

Palavras-chave: Fotobiomodulação; Cuidados de enfermagem; Protocolos clínicos; Extravasamento de antineoplásicos

\begin{abstract}
Objective: To demonstrate the use of the association of photobiomodulation with topical hyaluronidase in paclitaxel extravasation. Method: Case study referring to the use of photobiomodulation and topical hyaluronidase in a paclitaxel extravasation that occurred in the oncology clinic of a university hospital. After $450 \mathrm{ml}$ of paclitaxel infusion, the infusion pump stopped, edema on the site and displacement of part of the catheter from the puncture site was observed. Patient denied complaints of pain at the site and reported that he only observed the edema at the same time as the nursing team. The area was demarcated and presented an approximate measurement of $3.5 \mathrm{x} 3.0 \mathrm{~cm}$ (height $\mathrm{x}$ width). Results: After verifying the extravasation, all necessary measures were taken, following the institutional protocol. Nine photobiomodulation points were performed using 1 joule/cm2 as energy density, then topical hyaluronidase $65 \mathrm{UTR} / \mathrm{g}$ was administered. The patient was instructed about home care. Conclusion: The association of FBM with topical hyaluronidase maintained the integrity of the patient's skin, not forming lesions resulting from extravasation.
\end{abstract}

Keywords: Photobiomodulation; Nursing care; Clinical protocols; Extravasation of antineoplastic. 


\begin{abstract}
Resumen
Objetivo: Demostrar el uso de la asociación de fotobiomodulación con hialuronidasa tópica en la extravasación de paclitaxel. Método: Estudio de caso sobre el uso de fotobiomodulación e hialuronidasa tópica en una extravasación de paclitaxel ocurrida en la clínica de oncología de un hospital universitario. Después de $450 \mathrm{ml}$ de infusión de paclitaxel, la bomba de infusión se detuvo, se observó edema en el sitio y desplazamiento de parte del catéter del sitio de punción. El paciente negó quejas de dolor en el sitio e informó que solo observaba el edema al mismo tiempo que el equipo de enfermería, el área estaba demarcada y presentaba una medida aproximada de 3,5 x 3,0 cm (alto x ancho). Resultados: Luego de verificar la extravasación, se tomaron todas las medidas necesarias, siguiendo el protocolo institucional. Se realizaron nueve puntos de fotobiomodulación usando 1 julio $/ \mathrm{cm} 2$ como densidad de energía, luego se administró hialuronidasa tópica 65 UTR / g. Se instruyó al paciente sobre la atención domiciliaria. Conclusión: La asociación de FBM con hialuronidasa tópica mantuvo la integridad de la piel del paciente, no formando lesiones por extravasación.
\end{abstract}

Palabras clave: Fotobiomodulación; Cuidado de enfermera; Protocolos clínicos; Extravasación de antineoplásico.

\title{
1. Introdução
}

A quimioterapia (QT) atualmente é a terapêutica mais utilizada para o tratamento do câncer, podendo ser administrada por diversas vias, porém é a via endovenosa a mais comum. As particularidades dos quimioterápicos devem ser de conhecimento da equipe de enfermagem, principalmente na questão dos eventos adversos (Freitas, 2015).

O extravasamento de antineoplásicos é um evento adverso e pode ser considerado uma das principais emergências oncológicas, sendo definido como o escape acidental do quimioterápico vesicante para fora do vaso sanguíneo, abrangendo tecidos circunjacentes, podendo acontecer em acesso venoso periférico ou central. Possui uma incidência de 0,1 a $7 \%$ em infusão periférica e tem como principais sintomas a parada da infusão, dor, formação de vesículas, edema, queimação, desconforto local, eritema, necrose tissular e síndrome compartimental (Freitas, 2015; Kreidieh et al., 2016; Murayama et al., 2019; Maly et al., 2018).

Os quimioterápicos vesicantes são divididos em dois grupos, os ligantes ao DNA, que se ligam aos ácidos nucleicos dos tecidos, gerando radicais livres e inibindo a síntese de proteínas, ocorrendo a destruição progressiva do tecido. Como exemplos podemos citar as antraciclinas, antibióticos tumorais e alguns agentes alquilantes. O segundo grupo são as drogas vesicantes não ligantes ao DNA, sua atuação é diretamente sobre as células saudáveis do tecido, sendo brevemente metabolizada, portanto, facilmente neutralizadas. Esta classe é representada principalmente pelos taxanos e alcaloides da vinca (Freitas, 2015; Bonassa \& Gato, 2012).

O paclitaxel é classificado como antineoplásico não ligante ao DNA e sua aplicação é por via endovenosa e está indicada para tratamento de tumores de mama, ovário, câncer de pequenas células de pulmão e sarcoma de+ Kaposi (Lima, 2019).

Entretanto, o extravasamento desta droga pode causar lesões bolhosas e danos aos tecidos. Relatos encontrados na literatura indicam que a administração de vesicantes como paclitaxel, causam edema subcutâneo no local da punção que comprime a veia e impede o retorno venoso, dificultando a continuidade da infusão programada (Murayama et al., 2019).

Algumas práticas podem favorecer o extravasamento como a frequência elevada de punções em um mesmo local, o uso de veias pequenas e frágeis, erros técnicos na punção venosa periférica e na administração das drogas aplicadas ao tratamento. Portanto, cabe ao enfermeiro a melhor escolha do dispositivo para a punção, bem como a observação das características dos pacientes, principalmente idosos e crianças (Freitas, 2015).

Visto isso, observa-se uma demanda maior na tenacidade assistencial por parte do enfermeiro especialista em oncologia, onde a passividade e a falta de protocolos assistenciais diante da condução do extravasamento, pode mudar o prognostico do paciente, diminuindo consideravelmente a qualidade de vida. É imprescindível uma correta avaliação e 
intervenção precoce, por meio de protocolos bem definidos, além do desenvolvimento de programas de treinamento em quimioterapia, para melhoria da assistência ao paciente oncológico (Kapucu et al., 2017).

Os protocolos devem ser bem instituídos com antídotos que promovam a rápida disseminação do quimioterápico extravasado e amenize os efeitos dolorosos causados por este evento adverso (Freitas, 2015; Kapucu et al., 2017).

Em virtude destes desafios, observa-se que fotobiomodulação (FBM) ou Laser de Baixa Intensidade (LBI) pode ser empregada no manejo dos extravasamentos, pois é recomendada para acelerar o processo cicatricial e em diversas patologias, melhorando substancialmente a qualidade de vida do paciente. A FBM provoca reações no metabolismo celular, por meio de ação junto as mitocôndrias, ocorrendo um aumento na produção de ATP e favorecendo respostas biológicas, além de não causar efeitos colaterais ao organismo, caracterizando-se como um recurso terapêutico de baixo custo, muitas vezes de primeira escolha (Freitas et al., 2020; Gomes \& Schapochnik, 2017; Chamusca et al., 2012).

Ressalta-se que a aplicabilidade da FBM está ramificada em quatro domínios, sendo estes: a laserterapia sistêmica que contribui na ativação da imunidade, diminuição de radicais livres; terapia fotodinâmica (PDT), que é aplicada em feridas infectadas, fungos bactérias vírus; bioinibição, que tem ação analgésica e promove a modulação de edemas; e por final a bioestimulação que realiza a modulação do processo inflamatório, além de estimular a cicatrização (Freitas et al., 2020; Freitas et al., 2021; Lima, 2019; Lizarelli, 2018).

Visto que, a ação da FBM está inteiramente ligada a densidade de energia aplicada, o comprimento de onda e a potência do aparelho e que a padronização destes parâmetros, pode trazer efeitos para a melhora no processo de reparo celular (Freitas et al., 2020; Freitas et al., 2021). O objetivo deste relato de caso é demonstrar a associação da FBM com a hialuronidase tópica no extravasamento de paclitaxel.

\section{Metodologia}

A metodologia apresentada refere-se ao relato de caso de um paciente adulto, com 59 anos de idade, diagnosticado com CEC esôfago médio/distal com invasão de brônquio fonte esquerdo, síndrome anorexia-caquexia, alimentação exclusiva via jejunostomia, sem condições de RT devido ao risco de fistulização está em QT paliativa.

O paciente apresentou sinais de extravasamento de paclitaxel por acesso venoso periférico, sendo prontamente atendido pela equipe de enfermagem que iniciou as condutas frente a um extravasamento de antineoplásicos, para minimizar ou até mesmo excluir qualquer lesão tecidual.

Ressalta-se que a finalidade de um estudo de caso é agregar conhecimentos por meio da investigação detalhadas e sistemática sobre um evento ocorrido, transformando tal fato em conhecimento para o seu leitor (Patton, 2002).

Este relato de caso foi autorizado pelo Comitê de Ética e Pesquisa da Faculdade de Medicina de Botucatu, com o parecer 4.896.158.

\section{Relato de Caso}

Paciente L.C, natural do Paraná, procedente de Paranapanema, com 59 anos de idade, estudou até 4a série, autônomo (pedreiro, trabalhou com madeira), católico, aposentado. Solteiro, não tem filhos e mora sozinho. Histórico familiar de mãe com câncer de cólon. Nega comorbidades, uso de medicações de uso contínuo ou alergia a medicamentos. Tabagista desde os 17 anos, cigarro de corda e ex-etilista desde 2013.

Paciente Iniciou com quadro de disfagia para sólidos, realizando EDA e sendo diagnosticado com CEC moderadamente diferenciado, TxNxM0. Submetido em novembro de 2020 a jejunostomia. 
Foi encaminhado à Unidade de Infusão do Ambulatório de Oncologia do Hospital Estadual de Botucatu para iniciar a primeira sessão de tratamento quimioterápico no dia 29/01/2021, com proposta de quimioterapia paliativa de $1^{\text {a }}$ linha com esquema semanal de paclitaxel + carboplatina.

No dia 18/03/2021 compareceu para QT, foi puncionado acesso venoso periférico em região do antebraço direito (Figura 1) com íntima ${ }^{\circledR}$ número 22 e fixado com uma fita microporosa opaca, o que dificultou a visualização correta do local de punção. Após $450 \mathrm{ml}$ de infusão do paclitaxel, observou-se parada da bomba de infusão, edema no local e constatou-se deslocamento de parte do cateter do local da punção. Paciente negou queixas álgicas no local e relatou que somente observou o edema no mesmo momento da equipe de enfermagem (Figura 2).

Figura 1. Local da punção.

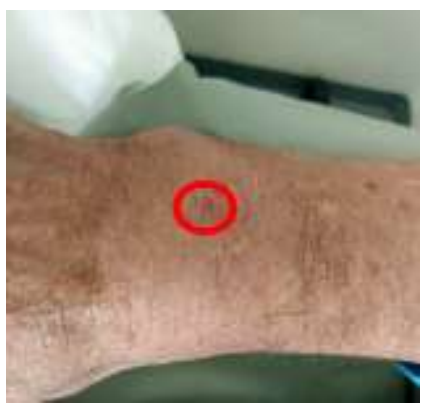

Fonte: Autores (2021).
Figura 2. Aspecto inicial do extravasamento.

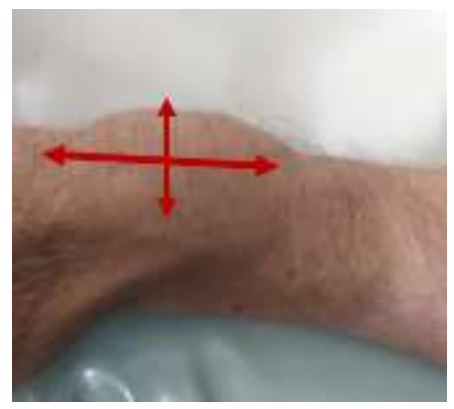

Fonte: Autores (2021).

O ambulatório de oncologia possui protocolo bem estabelecido e equipe treinada para o tratamento de extravasamentos de antineoplásicos. Imediatamente houve a parada da infusão, aspiração da droga no local do acesso por meio de seringa, retirada do acesso venoso, realizado FBM pontual 1J por ponto, sendo aplicado em nove pontos (Figuras 3), aplicação compressa morna no local da infusão por 20 minutos e após, administrado hialuronidase tópica 65 UTR/g.

Figura 3. Aplicação da FBM pontual $1 \mathrm{~J}$ por ponto - totalizando 9 pontos.

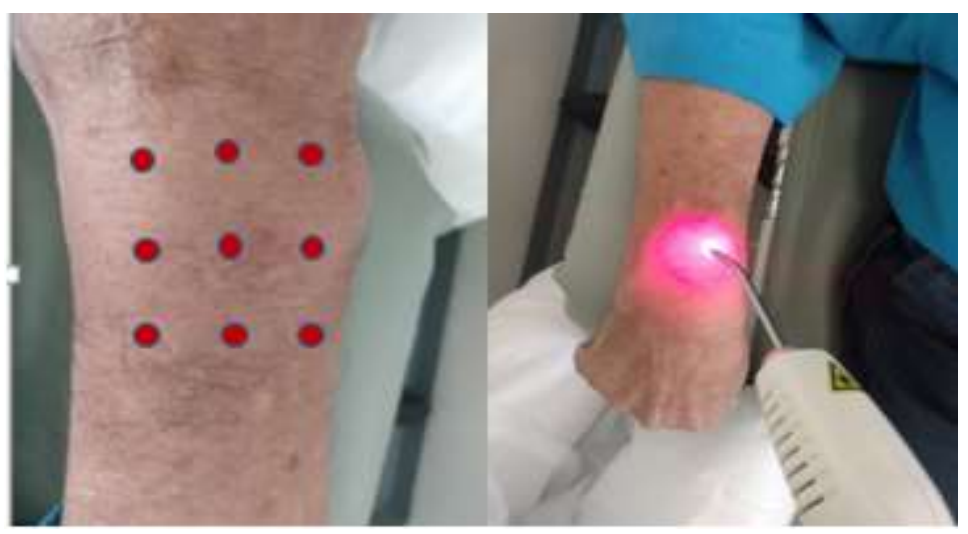

Fonte: Autores (2021).

Após, foi preenchido notificação de extravasamento de quimioterápicos no prontuário eletrônico do paciente, bem como realizada notificação de eventos adversos seguindo a rotina da instituição. 
Os cuidados domiciliares foram fortemente recomendados ao paciente e incluíam como realizar a aplicação de compressa morna três vezes ao dia por 48 horas, bem como aplicação da hialuronidase, após a compressa. Agendado retorno quatro dias após o extravasamento ao setor de oncologia para avaliação do local extravasado pela equipe de enfermagem.

Transcorrido quatro dias após o extravasamento, paciente não retornou ao serviço de oncologia, sendo realizado contato via telefone, porém sem sucesso. Após sete dias compareceu ao serviço para nova sessão de quimioterapia. Neste momento, foi avaliado e observado que não houve o surgimento de lesão, assim como não havia mais evidência do extravasamento. Portanto, observou-se que as condutas adotadas proporcionaram a manutenção da integridade da pele. Houve remissão completa do extravasamento de paclitaxel após uma aplicação de laserterapia associada aos demais cuidados propostos acima.

Importante salientar que após esse fato a rotina da Instituição foi alterada no sentido de escolha de uma melhor fixação de acesso venoso periférico, sendo protocolado o uso de filme transparente estéril.

Durante a avaliação após 7 dias (Figura 4) da área extravasada evidenciou-se o não surgimento de lesão, mantendo a pele íntegra, o que demonstra a eficiência nos métodos adotados no protocolo executado pela equipe assistencial do setor de oncologia.

Figura 4. Após 7 dias (18/03/2021).

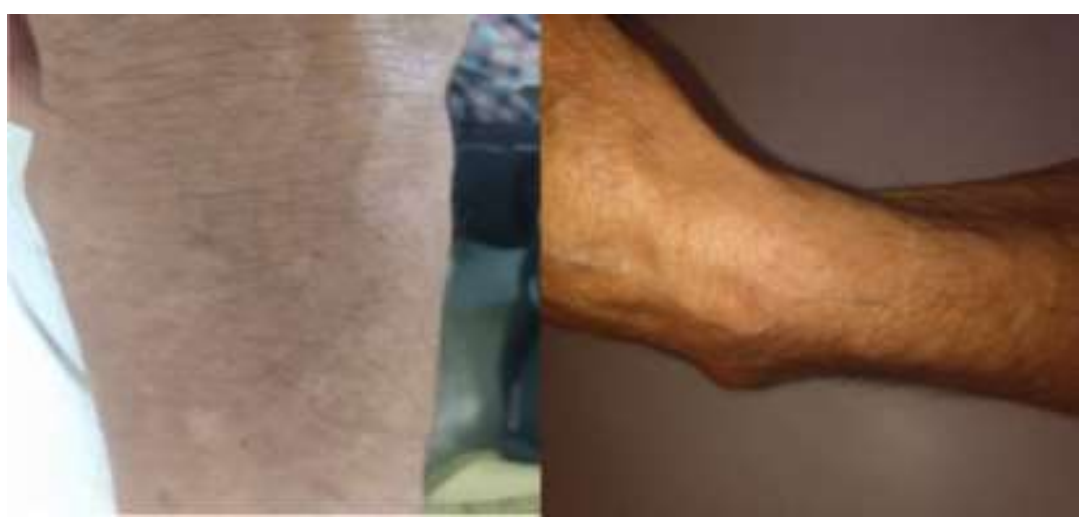

Fonte: Autores (2021).

\section{Discussão}

O quimioterápico paclitaxel é usualmente administrado para o tratamento de vários tipos de câncer, e sua principal via de infusão é a periférica, fato este que corrobora com estudos onde $73 \%$ dos extravasamentos ocorridos desta medicação foram em via periférica, enquanto $23 \%$ dos casos foram em cateter central (Barbee et al., 2014).

Os relatos de extravasamento deste medicamento, em relação tempo de melhora completa do local extravasado, apresentaram uma variação de 5 dias a 12 meses, a depender do local puncionado, tipo de punção (periférica ou acesso central), tempo de administração do quimioterápico, extensão do extravasamento e tratamento instituídos pós extravasamento (Barbee et al., 2014; Stanford \& Hardwicke, 2003).

Os danos teciduais pós extravasamento relatados na literatura referentes a está medicação denotam a presença de dor, edema, eritema, sensibilidade local, vesículas, celulites com ou sem necrose, e em algumas circunstâncias, havendo a necessidade de intervenção cirúrgica e introdução de antibioticoterapia para resolução dos casos (Freitas, 2015; Stanford \& Hardwicke, 2003). 
Outra recomendação pouco descrita na literatura, é sobre a fixação do cateter com cobertura transparente, uma vez que esta facilita a visualização da punção e avaliação precoce de sinais de extravasamento, a fim de evitar que haja lesões teciduais graves e posteriormente a interrupção do tratamento para a doença de base (Bonassa \& Gato, 2012; Lima, 2019; Vasques et al., 2018). Fato esse que corrobora com o encontrado no relato descrito acima, mostrando que a fixação do dispositivo é de extrema importância para a segurança do paciente.

O extravasamento de paclitaxel pode ocasionar danos estéticos e funcionais graves, afetando diretamente a qualidade de vida do paciente envolvido, além de afetar indiretamente o prognostico do paciente (Freitas, 2015; Freitas et al., 2020).

Portanto, é fundamental que pacientes e cuidadores, sejam protagonistas durante o tratamento, sendo importante que este seja devidamente orientado, quanto aos riscos de complicações envolvidas na administração de drogas vesicantes, para que o paciente, relate previamente qualquer sintoma de dor, desconforto, edema e queimação na região da punção venosa (Bonassa \& Gato, 2012; Lima, 2019).

A enfermagem desempenha um papel ativo na prevenção de extravasamento de quimioterápicos. Deve dispor de conhecimentos sobre a classificação dos quimioterápicos vesicantes, os principais sintomas verbalizados pelo paciente, assim como a escolha correta do acesso venoso, local correto para punção, além de saber conduzir o tratamento apropriado mediante a um extravasamento (Pelissa \& Nothaft, 2019).

A elaboração de protocolos bem desenhados fundamentados em evidências científicas, podem minimizar os riscos de extravasamento (Lima, 2019; Freitas et al., 2020). Portanto, destaca-se que o atendimento descrito, encontra-se dentro dos padrões recomendado pela literatura nacional e internacional promovendo a continuidade do tratamento proposto e sem demais adversidades.

A implementação de novas tecnologias como a FBM traz um novo padrão ao tratamento do extravasamento de antineoplásicos, garantindo a conduta adequada frente a prevenção da formação de lesões.

Apesar de ser escassa esta temática na literatura, um estudo cita a aplicação da FBM com a técnica pontual utilizando-se 1 joule vermelho, com associação de compressa quente ou fria, elevação do membro e aplicação do antídoto hialuronidase, foram efetivos para os 15 pacientes avaliados (Freitas et al., 2020), atribuindo autenticidade a narrativa descrita acima.

Frisando que a enfermagem está respaldada pelo Conselho Regional e Federal de Enfermagem na introdução da FBM em suas atividades, desde que apresente conhecimento prévio, nas áreas da física, biofotônica, interação do laser com os tecidos biológicos, dosimetria, além de conhecimento aprofundado em fisiologia (Lima, 2019; COREN, 2014; COREN, 2018).

Por conseguinte, verificamos a importância da atuação da enfermagem a favor do tratamento e da manutenção da qualidade dos pacientes assistidos, assim como a aderência do paciente ao tratamento proposto, sendo ele um protagonista fundamental nesta temática.

\section{Conclusão}

A associação da FBM com a hialuronidase tópica, manteve a integridade da pele do paciente, não formando lesões. Em face dos aspectos abordados, é de extrema importância a qualificação das equipes de saúde, envolvidos em todo o processo da terapia com drogas quimioterápicas antineoplásicas. Protocolos que possam destacar esta temática devem ser instituídos, buscando reduzir os riscos de lesões e aumentando a qualidade de vida do paciente. A inserção da FBM, tem se mostrado benéfica.

Desta forma, é indispensável a capacitação dos enfermeiros em FBM por meio de curso ou até mesmo especialização com grade curricular pré-definida e que contemple os requisitos exigidos pelo COREN e COFEN, garantindo a assistência pautada na enfermagem baseada em evidências. 


\section{Referências}

Barbee, M. S., Owonikoko, T. K., \& Harvey, R. D. (2014). Taxanes: vesicants, irritants, or just irritating?.Therapeutic advances in medical oncology, 6(1), 16-20. https://doi.org/10.1177/1758834013510546

Bonassa, E. M. A., \& Gato, M. I. R. (2012). Terapêutica Oncológica para Enfermeiro e Farmacêuticos. (4a ed.). Editora Atheneu.

Chamusca, F. V., Reis, S. R. A., Lemaire, D., \& Medrado, A. P. (2012). Mediadores do efeito sistêmico do processo inflamatório e terapias fotobiomoduladoras: uma revisão de literatura. Revista De Ciências Médicas E Biológicas, 11(1), 70-78. https://doi.org/10.9771/cmbio.v11i1.5705

Conselho Regional de Enfermagem de São Paulo (COREN). (2014). Parecer COREN-SP 009/2014. Utilização do Laser de Baixa Intensidade (LBI) pelo enfermeiro. https://portal.coren-sp.gov.br/sites/default/files/Parecer_009_Utilizacao_Laser_Baixa_Intensidade_LBI_por_enfermeiro.pdf

Conselho Regional de Enfermagem de São Paulo (COREN). (2018). Parecer COREN-SP 009/2018. Ementa: Laser Vermelho e Infra Vermelho. https://portal.coren-sp.gov.br/wp-content/uploads/2019/01/parecer-009-2018.pdf

Freitas, K. A. B. S. (2015). Estratégias para a administração segura de antineoplásicos [dissertação de mestrado]. Botucatu (BR): Universidade Estadual Paulista, Faculdade de Medicina de Botucatu. http://hdl.handle.net/11449/134240

Freitas, K. A. B. S., Minicucci, E. M., Bragnato, V. S., \& Lizarelli, R. de F. Z. (2021). Association of different approaches to low level laser therapy in the treatment of surgical dehiscence of knee arthroplasty. Research, Society and Development, 10(11), e505101119757. https://doi.org/10.33448/rsd-v10i11.19757

Freitas, K. A. B. S., Minicucci, E. M., Lima, T. O., Silva, K. A. B., Menozzi, B. D., Silva, V. F. B., \& Popim, R. C. (2021). Effects of photobiomodulation (low-intensity laser) on wound healing: an integrative review. Research, Society and Development, 10(11), e362101119821. https://doi.org/10.33448/rsdv10i11.19821

Freitas, K. A. B. S., Oliveira de Lima, T., Beluomini de Castro, A., Batista da Silva, K. A., Passarelli Vigliassi, A., \& Popim, R. C. (2020). Elaboração e implantação de protocolo de condutas no extravasamento de medicamentos não quimioterápicos. Saúde Coletiva (Barueri), 10(58), 3913-3922. https://doi.org/10.36489/saudecoletiva.2020v10i58p3913-3922

Gomes, C. F. G., \& Schapochnik, A. (2017). O uso terapêutico do LASER de Baixa Intensidade (LBI) em algumas patologias e sua relação com a atuação na Fonoaudiologia. Distúrb Comun, 29(3), 570-578. https://doi.org/10.23925/2176-2724.2017v29i3p570-578

Kapucu, S., Özkaraman, A. Ö., Uysal, N., Bagcivan, G., Şeref, F. Ç., \& Elöz, A. (2017). Knowledge Level on Administration of Chemotherapy through Peripheral and Central Venous Catheter among Oncology Nurses. Asia-Pacific journal of oncology nursing, 4(1), 61-68. https://doi.org/10.4103/23475625.199081

Kreidieh, F. Y., Moukadem, H. A., \& El Saghir, N. S. (2016). Overview, prevention and management of chemotherapy extravasation. World Journal Clinical Oncology, 1(7), 87-97. https://doi.org/10.5306/wjco.v7.i1.87

Lima, R. F. (2019). Elaboração e validação do Manual de Orientações sobre reações adversas a antineoplásicos para a Equipe de Enfermagem [dissertação de mestrado]. Natal (BR): Hospital das Clínicas de Porto Alegre. Recuperado de http://hdl.handle.net/10183/199303

Lima, T.O. (2019). Eficácia da laserterapia trasncutânea sobre efeitos adversos da quimioterapia: ensaio clínico randomizado. [dissertação de mestrado]. Botucatu (BR): Universidade Estadual Paulista, Faculdade de Medicina de Botucatu. Recuperado de http://hdl.handle.net/11449/190978

Lizarelli, R. F. Z. (2018). Reabilitação biofotônica orofacial: fundamentos e protocolos clínicos. Compacta

Maly, C., Fan, K. L., Rogers, G. F., Mitchell, B., Amling, J., Johnson, K., Welch, L., Oh, A. K., \& Chao, J. W. (2018). A Primer on the Acute Management of Intravenous Extravasation Injuries for the Plastic Surgeon. Plastic and reconstructive surgery. Global open, 6(4), e1743. https://doi.org/10.1097/GOX.0000000000001743

Murayama, R., Oya, M., Abe-Doi, M., Oe, M., Komiyama, C., \& Sanada, H. (2019). Characteristics of subcutaneous tissues at the site of insertion of peripheral infusion in patients undergoing paclitaxel and carboplatin chemotherapy. Drug discoveries \& therapeutics, 13(5), 288-293. https://doi.org/10.5582/ddt.2019.01064

Patton, M. Q. (2002). Qualitative research \& evaluation methods. (3a ed.). Sage Publications.

Pelissa, A., \& Nothaft, S. C. S. (2019). Extravasamento quimioterápico e as condutas adotadas pela equipe de enfermagem: uma revisão integrativa. Universidade Regional Integrada do Alto Uruguai e das Missões. http://repositorio.uricer.edu.br/handle/35974/252

Stanford, B. L., \& Hardwicke, F. (2003). A review of clinical experience with paclitaxel extravasations. Supportive care in cancer: official journal of the Multinational Association of Supportive Care in Cancer, 11(5), 270-277. https://doi.org/10.1007/s00520-003-0441-0

Vasques, C. I., Custódio, C. S., Goulart, C. B., Silveira, R. C. C. P., Santos, B. N., \& Santos, K. R. M. (2018). Diretrizes Oncológicas: Acessos Vasculares em Oncologia (2nd ed.). DoctorPress. 